Bond University

Research Repository

\title{
Utilising Anatomical and Physiological Visualisations to Enhance the Face-to-Face Student Learning Experience in Biomedical Sciences and Medicine
}

Moro, Christian; Gregory, Sue

Published in:

Biomedical Visualisation

DOI:

10.1007/978-3-030-19385-0_3

Licence:

Other

Link to output in Bond University research repository.

Recommended citation(APA):

Moro, C., \& Gregory, S. (2019). Utilising Anatomical and Physiological Visualisations to Enhance the Face-to-

Face Student Learning Experience in Biomedical Sciences and Medicine. In P. Rea (Ed.), Biomedical

Visualisation (Vol. 3, pp. 41-48). (Advances in Experimental Medicine and Biology; Vol. 1156). Springer. https://doi.org/10.1007/978-3-030-19385-0_3

\section{General rights}

Copyright and moral rights for the publications made accessible in the public portal are retained by the authors and/or other copyright owners and it is a condition of accessing publications that users recognise and abide by the legal requirements associated with these rights.

For more information, or if you believe that this document breaches copyright, please contact the Bond University research repository coordinator 


\title{
Utilising anatomical and physiological visualisations to enhance the face-to-face student learning experience in biomedical sciences and medicine
}

Christian Moro ${ }^{1}$ and Sue Gregory ${ }^{2}$

\author{
Affiliations \\ ${ }^{1}$ Christian Moro. Faculty of Health Sciences and Medicine, Bond University Gold Coast QLD \\ 4229.cmoro@bond.edu.au. \\ ${ }^{2}$ Sue Gregory. University of New England, Armidale, NSW 2351.sue.gregory@une.edu.au
}

\begin{abstract}
The introduction of online learning and interactive technology into tertiary education has enabled biomedical science and medical faculties to provide students with quality resources for off-campus study. This encompasses online self-directed learning, interactive blogs, quizzes, recordings of lectures and other resources. In addition, textbooks are now supplemented with interactive online learning tools, meaning that the student now has more accessibility than ever to engage with content. However, in biomedical sciences and medicine, technology has also enhanced the in-classroom experience. Anatomical and physiological visualisations in virtual, augmented and mixed reality provide students with an unprecedented ability to explore virtual content in-class, while learning remains structured by the facilitator and teaching team. This chapter will provide insights into the past use of technology to enhance off-campus learning, and then focus on the range of visualisations utilised within the laboratory or classroom in order to facilitate learning in biomedical sciences and medicine, including: augmented reality, virtual reality; mixed reality and Holograms; 3D printing; simulated dissections and anatomy simulation tables; and "Smart" tablets and touchscreen devices.
\end{abstract}

Keywords: Virtual Reality, Augmented Reality, Educational Technology, Mixed Reality, Hololens, Medical Education. 


\subsection{The phenomenal rise of off-campus/online learning}

The rise of Massive-Open Online courses (MOOCs) has meant that thousands of students no longer need to physically attend a university in order to receive instruction. Over 900 universities offer 11,400 MOOCs, with enrolments of over 100 million students (Shah 2018). Of these, it is estimated that over 50\% are studying within a Science, Technology, Engineering or Mathematics (STEM) discipline (Shah 2018). The motivation for this phenomenal rise appears varied, such as from the desire to modernise, redesign curriculum and capitalise on promotional opportunities (O’Connor 2014). There are other driving factors for universities (providers) to roll out MOOCs, with governments increasingly creating policy and funding to stimulate development in the online market. For example, the Australian Trade and Investment Commission's International educational roadmap strategizes for the enrolment of 110 million international students by 2025 (Australian Government 2016) and increasingly incentivises educational providers and industry wishing to enter this space. However, educators have genuine concerns over the rise of MOOCs. There is a lack of consistent engagement between students and instructors in any MOOC, and students appear somewhat reluctant to even communicate with each other to the extent that they do in face-to-face or traditional online classes (Hew et al. 2018). The student expectations within a MOOC are highly varied, meaning that students often do not know what to anticipate when enrolling (Littlejohn et al. 2016). Instructors are also concerned about the future of MOOCs for online learning, with many considering them far less effective as face-to-face learning (Lowenthal et al. 2018). It extends far beyond the simple course, with university-hosted MOOC-based online degrees, already enrolling over 9000 students. This means that students increasingly have the option to hold their entire tertiary educational journey, online, and without any face-to-face instruction.

The methods employed when using MOOCs as educational tools are varied. Some MOOC studies are increasingly drawing on sources of information outside the set course material, such as content posted on social media (Bicen 2017). However, with course content and interaction with the instructor being two of the major factors enticing students to remain enrolled within a MOOC (Hone and El Said 2016), the use of offsite or outside information risks lowering retention rates. This is an important consideration, as student retention remains an important challenge for MOOC developers and providers. Some studies have suggested that up to $90 \%$ of students enrolled in MOOCs dropout (Alraimi et al. 2015). However, this number may be unrepresentative, as some students may enrol in a MOOC to "browse" (Reich 2014), or are 
there solely for the content and less interested in completing any required assessments (Greene et al. 2015). Although the retention rates are alarmingly low, it may not be a suitable measurement for assessing MOOCs compared to traditional university subjects (DeBoer et al. 2014).

Besides MOOCs, the general trend of educational technology appears to be moving towards the ability to facilitate and enable off-campus learning. Technologies surrounding selfdirected learning, interactive blogs, quizzes, recordings of lectures and other resources are increasingly invested in by universities, industry, publishers and Educational Technology (EdTech) providers. This allows scalability of resources, accessibility to information and selfpaced learning experiences for students regardless of location, even if this trend challenges librarians who deal with the copyright and licencing of these products (Gore 2014). At the other end of the spectrum, educational technology is increasingly being employed to enhance faceto-face learning on campus. This fusion of sessions facilitated by both technology and an instructor has had a much slower adoption than online learning yet is able to provide many of the benefits of online learning, such as the self-paced and individualised environment, into the classroom. This is particularly important in medicine and biomedical sciences anatomy and physiology education, where students require an understanding of the human body in a 3D space. Technology shown to be effective in this space includes augmented, virtual and mixed reality, holograms, 3D Printing, simulated dissections and simulation tables, as well as interactive tablets and touchscreen devices.

The use of technology in teaching has also facilitated a genuine trend in higher education and medical health education away from the traditional education practice of didactic lectures and tutorials, towards group-based (Moro and McLean 2017), self-directed (Murad et al. 2010) and online education (Clark and Mayer 2016). There is also a range of upcoming technological innovations which may positively benefit teaching. This includes mixed reality (MR) through devices such as the Microsoft HoloLens. For students, technology enables access to course content at any place or time, and for educators, it expands their ability to educate well away from the classroom or lecture hall setting (Goh 2016). These are the exciting trends in educational technology. It also enables educators to teach using multiple modes, which is particularly important in anatomy or health care education (Estai and Bunt 2016). 


\subsection{History of off-campus/distance/online education}

Learning from a distance (or off-campus), as it was in the 1970s, was through products received in the post (mail) such as printed reading materials and assessment tasks utilising audio cassette tapes, which housed dialogue from the lecturer (Maroto-Alfar and Durán-Gutiérrez 2016). Digital resources came to the fore in the late $20^{\text {th }}$ century for online education through the use of chat rooms (which began in the 1970s), discussion boards (earliest began in 1985), blogs (as early as 1994) and wikis (in 1994, and Wikipedia in 2001), all enhancing the online interaction between student/lecturer and student/student. Social media was also being used as a tool to engage students with more learnings, such as LinkedIn in 2002, Facebook in 2004, and YouTube in 2005. More immersive technologies started evolving, being added to the list of tools used by lecturers in the mid-2000s, for example, through the use of a virtual world such as Second Life, which was created in 1994 but only became available for commercial use in 2003 and educational purposes in 2006. There are now more than 200 virtual worlds, and many institutions create their own for use with their students. The success of a virtual world for teaching and learning is well documented for both online and on-campus students. Virtual worlds were used as a low-cost space substituting real world (Gregory and Tynan 2009). For online students, the students felt like they were there, in the same space, at the same time and with their peers.

An extensive pilot research from 2008-2011 of 3,576 students demonstrated the positive impact of using a virtual world for teaching and learning, with results indicating that voluntary virtual world groups academically out-performed the non-virtual world group of initial teacher education students (79.3\%), with those who chose to learn using a virtual world attaining a grade of $75 \%$ or higher, compared with $46.5 \%$ of those who chose not to study using the virtual world achieving this grade (Gregory 2013). Since this 2008-2011 research, digital technologies have advanced, and we can now build virtual classrooms to monitor how this type of teaching and learning is progressing through various other technologies. Figure 1 provides an image of 
a virtual class being undertaken by an initial teacher education students with a classroom of non-player characters (bots), who are programmed to respond to the teacher.

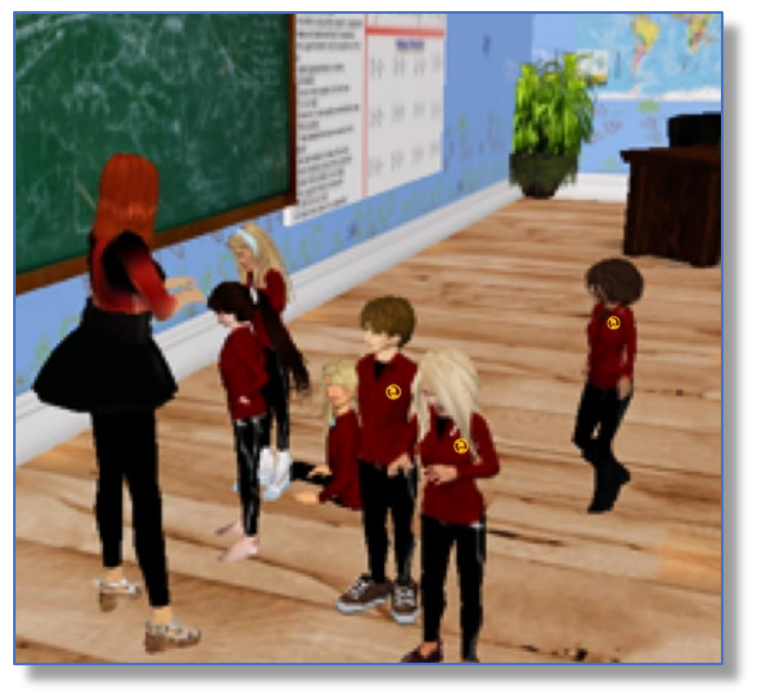

Figure 1: Virtual class of bots (non-player characters) being taught by an initial teacher education student through their avatar.

Through a comprehensive research project of initial teacher education student's perceptions of learning in a virtual world between 2008-2011, where over 40,000 lines of text were analysed, several themes emerged. These were that students felt that learning through a virtual world was engaging, it was an important component of communication for learning, the ability to be anonymous was important to be able to communicate without bias, the tyranny of distance was overcome to a large extent and the students felt a stronger sense of interaction and collaboration (Gregory 2012). However, they did feel that there were distractions in the virtual world that took them off task and that sometimes, the technology let them down.

\subsection{Technology today}

Since the times of the virtual world education, augmented, virtual, mixed reality and a variety of other technologies have been created to provide an even more immersive experience for students. To provide a better sense of these technologies, the following section defines what each one is, briefly.

- In virtual reality (VR), the user's senses (sight, hearing, and motion) are fully immersed in a synthetic environment that mimics the properties of the real world through high resolution, high refresh rate head-mounted displays, stereo headphones and motiontracking systems (Moro et al. 2017a; Moro et al. 2017b). This technology enables an 
individualised learning experience, even in a busy or noisy laboratory or teaching environment.

- Augmented reality (AR), through the use of a camera and screen (i.e., smartphone or tablet) digital models are superimposed into the real-world. The user is then able to interact with both the real and virtual elements of their surrounding environment (Birt et al. 2018).

- Three-dimensional (3D) displays utilize high-resolution screens on tablets and smartphones to visualize pseudo-3D models and environments. The user interacts with digital aspects on the screen and manipulates objects using a mouse or finger gestures.

- Mixed reality (MR), a continuum of these innovative technologies, combines the real and virtual words through head-mounted see-through displays and strong processing power, which allows for visualizations at different and multiple scales and the design and implementation of comparative mixed reality pedagogy across multiple disciplines.

\subsection{Modern technology's impact on medicine and biomedical science learning experiences in anatomy and physiology}

As described, technology has largely been employed to enhance off-campus learning in universities. There is increasing interest within faculties to invest in technology that enhances the face-to-face experience. Students are no longer content with a single lecturer orating the content in front of a large audience, and instead, expect interactive, engaging learning where they can fully participate with educators and staff. However, achieving this goal is difficult when managing a large-group cohort. As such, technology can bridge this gap between a single instructor being the sole provider of information to students interacting with various modes of delivery. Providing a portion of lesson content through technology-enhanced modes enables students to have a self-directed structured and interactive lesson, even within a large class size. When used by students during normal sessions, modern educational devices and technologies may also negate some of the negative impacts of having large class sizes, and assist with the student perception towards the receipt of an individualised learning experience (Cash et al. 2017; Monks and Schmidt Robert 2011). 
One mode of learning useful to biomedical sciences and medicine is through virtual reality. The learner can be entirely immersed in a virtual space with depictions of human anatomical structures or physiological processes (Figure 2). As virtual reality allows a way to block out all outside interference, distractions from other students or the classroom environment can be negated, and the student can focus on the learning at hand. Virtual reality, therefore, maintains a consistent learning environment, regardless of the size of the class or number of other students working in the vicinity. Virtual reality is increasingly being used to provide students with anatomical knowledge. One point for educators to consider, however, with virtual reality, is the impact of motion sickness on some learners during or after its use (Moro et al. 2017b).

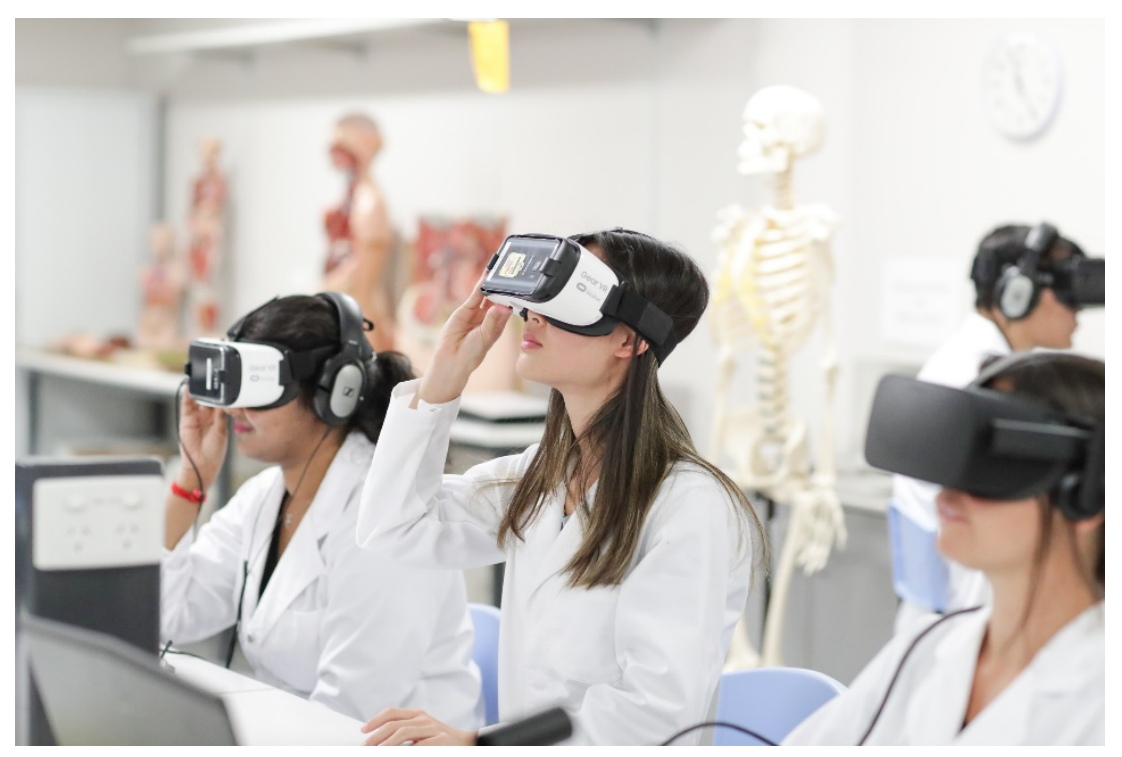

Figure 2: Students learning from within Virtual Reality in an anatomy and physiology class.

Augmented reality, on the other hand, does not cause any motion sickness or adverse effects (Moro et al. 2017a). By interacting with the object through a camera on a smartphone or tablet, the user remains in their physical environment and visualises any renderings via the screen (Figure 3). Students can wear headphones to receive audio content, allowing the instructor to provide lessons or instructions that are interactive and self-directed for the student's investigation. The interactivity of this technology, such as by removing or adding layers to an anatomical model or feature, can set the pace of learning within AR and enables a self-directed speed of instruction to each student within a diverse cohort (Birt et al. 2018). AR can also be used to simulate real-life surgical or medical procedures, such as intubation, suturing or phlebotomy. 


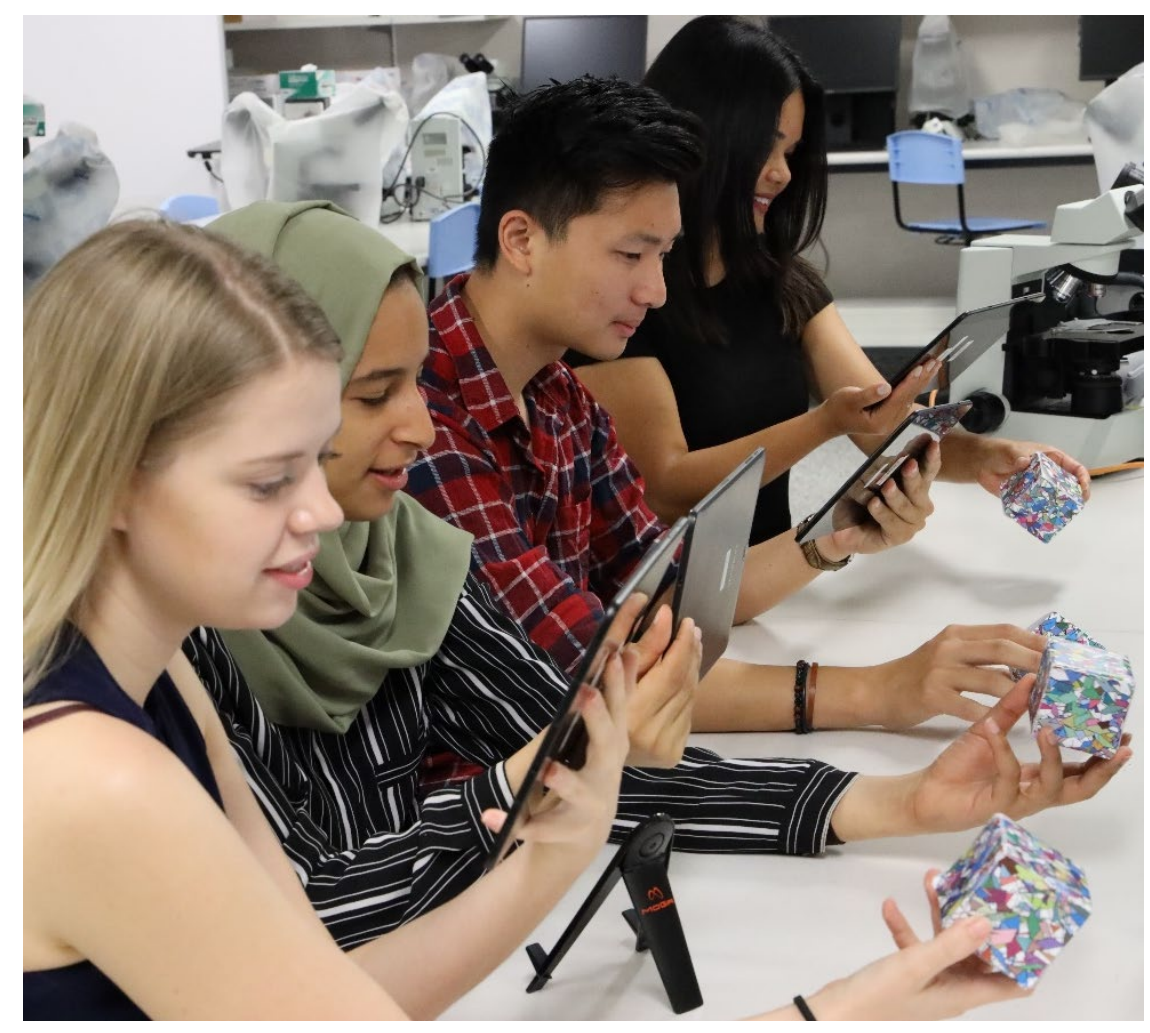

Figure 3: Students utilising Augmented Reality through a tablet, where the 3D printed marker becomes a visualised model of the brain on the tablet screen.

The most recent development in educational technology is from mixed reality. This is a fusion of virtual and augmented reality and requires specialised headsets. The most utilised of these is the Microsoft HoloLens (Figure 4), which allows students to visualise holographic visualisations of human anatomical structures in front of them. These devices can be connected together, with learners able to work with the educator to dissect a model or navigate through features of the human body. The fact that the room or environment the user is in remains visible, unlike in virtual reality, means that the issues of dizziness or cybersickness so often reported in virtual reality is largely minimised. Additionally, the use of mixed reality headsets also allows the user's hands to be free, to write notes, ask questions or interact with the models displayed on the screen. 


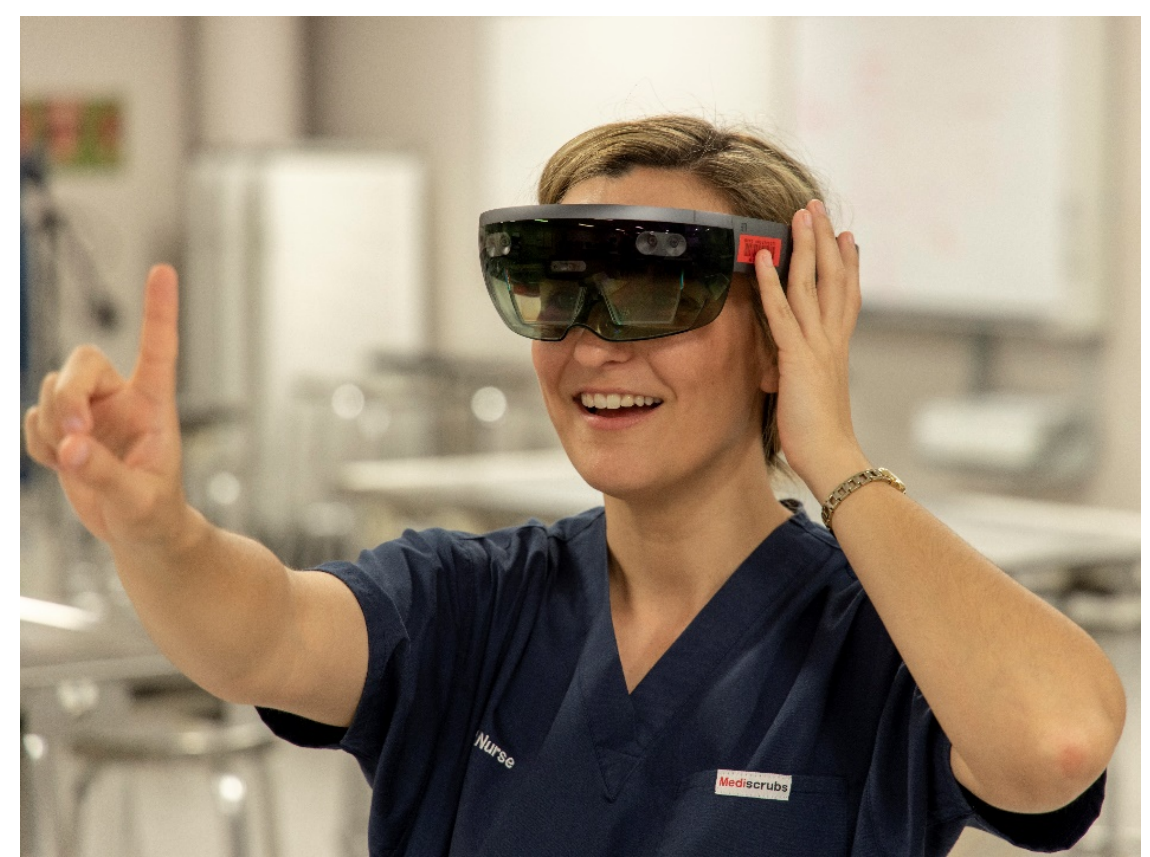

Figure 4: A student views holograms through the HoloLens which within an anatomical class revising the human brain.

Anatomical and physiological visualisations in virtual, augmented and mixed reality provide students with an unprecedented ability to explore virtual content in-class, while learning remains structured by the facilitator and teaching team. It also allows simple and rapid changing of models or visualisation modes, which is very useful for the depiction of anatomical variations or to demonstrate structures being dissected in real-time.

A range of other technologies are also being introduced to enhance the on-campus learning experience in medicine and biomedical science teaching sessions. This includes 3D printing, which can be used to show anatomical variations or to be tailored to depict a wide range of diseases or patient characteristics (Garcia et al. 2018). Alternatively, the Virtual Dissection Boards, such as the "Anatomage" Table, can visualise the dissection process using imagery instead of cadavers or donated human specimens. Increasing numbers of biomedical and medical departments utilise technology-enhanced learning to supplement their face-to-face lessons, and it has been the individual learners who have benefited. 


\section{Conclusion}

While technology has been increasingly utilised by universities to facilitate off-campus learning in the past, recent years have seen its introduction into on-campus learning experiences. This has created not only the ability for educators to provide structured, modern and individualised sessions, but also allowed students alternative ways to learn during teacherdirected sessions. This has included the introduction of virtual, augmented and mixed reality to the anatomy and physiology labs, as well as 3D printing, and even virtual dissections through interactive tables and screens. This use of educational technology within the laboratory or learning sessions is the start of an exciting time, where students are likely to be taught not solely by a single academic, but through a mixture of real-life and virtual modes of learning, all working concurrently to provide a modern, interactive learning experience. 


\section{References:}

Alraimi KM, Zo H, Ciganek AP (2015) Understanding the MOOCs continuance: The role of openness and reputation Computers \& Education 80:28-38 doi: https://doi.org/10.1016/j.compedu.2014.08.006

Australian Government (2016) National Strategy for International Education 2025 (AIE2025). http://nsie.education.gov.au/

Bicen H (2017) Determining the effect of using social media as a MOOC tool Procedia Computer Science 120:172-176 doi: https://doi.org/10.1016/j.procs.2017.11.225

Birt J, Stromberga Z, Cowling M, Moro C (2018) Mobile Mixed Reality for Experiential Learning and Simulation in Medical and Health Sciences Education Information 9:31

Cash CB, Letargo J, Graether SP, Jacobs SR (2017) An Analysis of the Perceptions and Resources of Large University Classes CBE life sciences education 16:ar33 doi: $10.1187 /$ cbe.16-01-0004

Clark RC, Mayer RE (2016) E-learning and the science of instruction: Proven guidelines for consumers and designers of multimedia learning. John Wiley \& Sons,

DeBoer J, Ho AD, Stump GS, Breslow L (2014) Changing “Course”:Reconceptualizing Educational Variables for Massive Open Online Courses Educational Researcher 43:74-84 doi: $10.3102 / 0013189 \times 14523038$

Estai M, Bunt S (2016) Best teaching practices in anatomy education: A critical review Annals of Anatomy - Anatomischer Anzeiger 208:151-157 doi: http://dx.doi.org/10.1016/j.aanat.2016.02.010

Garcia J, Yang Z, Mongrain R, Leask RL, Lachapelle K (2018) 3D printing materials and their use in medical education: a review of current technology and trends for the future BMJ simulation \& technology enhanced learning 4:27-40 doi: 10.1136/bmjstel-2017-000234

Goh PS (2016) eLearning or technology enhanced learning in medical education-Hope, not hype Medical Teacher 38:957-958 doi: 10.3109/0142159X.2016.1147538

Gore H (2014) Massive Open Online Courses (MOOCs) and Their Impact on Academic Library Services: Exploring the Issues and Challenges New Review of Academic Librarianship 20:4-28 doi: 10.1080/13614533.2013.851609

Greene JA, Oswald CA, Pomerantz J (2015) Predictors of Retention and Achievement in a Massive Open Online Course American Educational Research Journal 52:925-955 doi: $10.3102 / 0002831215584621$ 
Gregory S (2012) Learning in a virtual world: Student Perceptions and Outcomes. In: Moyle KW, G (ed) Student Reactions to Learning with Technologies: Perceptions and Outcomes vol 1. IGI Global, Hershey Pennsylvania, pp 91-116

Gregory S (2013) Comparison of Students Learning in a Virtual World. In: P. Jerry NT-J, \& S. Gregory (ed) The Hype Cycle Upswing: The Resurgence of Virtual Worlds InterDisciplinary Press, Oxford, United Kingdom, pp 123-134

Gregory S, Tynan B (2009) Introducing Jass Easterman: My Second Life learning space. In: Atkinson R, McBeath A (eds) Same Places, Different Spaces. Proceedings ascilite Auckland The University of Auckland, Auckland University of Technology, and ascilite, Auckland, New Zealand, pp 377-386

Hew KF, Qiao C, Tang Y (2018) Understanding Student Engagement in Large-Scale Open Online Courses: A Machine Learning Facilitated Analysis of Student's Reflections in 18 Highly Rated MOOCs 201819 doi: 10.19173/irrodl.v19i3.3596

Hone KS, El Said GR (2016) Exploring the factors affecting MOOC retention: A survey study Computers \& Education 98:157-168 doi: https://doi.org/10.1016/j.compedu.2016.03.016

Littlejohn A, Hood N, Milligan C, Mustain P (2016) Learning in MOOCs: Motivations and self-regulated learning in MOOCs The Internet and Higher Education 29:40-48 doi: https://doi.org/10.1016/j.iheduc.2015.12.003

Lowenthal P, Snelson C, Perkins R (2018) Teaching Massive, Open, Online, Courses (MOOCs): Tales from the Front Line 201819 doi: 10.19173/irrodl.v19i3.3505

Maroto-Alfar S, Durán-Gutiérrez Y (2016) Responsive Web Design: Experience at the National Distance University of Costa Rica. In: Dyson LE, Ng W, Fergusson J (eds) Mobile Learning Futures - Sustaining Quality Research and Practice in Mobile Learning:15th World Conference on Mobile and Contextual Learning, mLearn The University of Technology, Sydney, Sydney, Australia, pp 183-190

Monks J, Schmidt Robert M (2011) The Impact of Class Size on Outcomes in Higher Education vol 11. doi:10.2202/1935-1682.2803

Moro C, McLean M (2017) Supporting Students' Transition to University and Problem-Based Learning Medical Science Educator 27:353-361 doi: 10.1007/s40670-017-0384-6

Moro C, Stromberga Z, Raikos A, Stirling A (2017a) The effectiveness of virtual and augmented reality in health sciences and medical anatomy Anatomical sciences education 10:549-559 doi: 10.1002/ase.1696 
Moro C, Štromberga Z, Stirling A (2017b) Virtualisation devices for student learning: Comparison between desktop-based (Oculus Rift) and mobile-based (Gear VR) virtual reality in medical and health science education 201733 doi: 10.14742/ajet.3840

Murad MH, Coto-Yglesias F, Varkey P, Prokop LJ, Murad AL (2010) The effectiveness of self-directed learning in health professions education: a systematic review Medical Education 44:1057-1068 doi: 10.1111/j.1365-2923.2010.03750.x

O’Connor K (2014) MOOCs, institutional policy and change dynamics in higher education Higher Education 68:623-635 doi: 10.1007/s10734-014-9735-z

Reich J (2014) MOOC Completion and Retention in the Context of Student Intent.

Shah D (2018) By The Numbers: MOOCS in 2017. https://www.classcentral.com/report/mooc-stats-2017/. Accessed 25/09/2018 2018 